\section{Das Geburtsdatum sagt etwas über das Allergierisiko aus}

\author{
Schon früher wurde kursorisch immer wieder gezeigt, dass Kinder, die im \\ Frühjahr geboren wurden, höhere Raten an Pollinosis und weiteren allergi- \\ schen Reaktionen aufwiesen. Eine italienische Forschergruppe hat nun die \\ Aufnahmediagnosen in einer Notfallambulanz mit den jeweiligen Geburts- \\ tagen verglichen.
}

D ie Autoren durchforsteten für ihre Studie die elektronische Krankenhaus-Datenbank der Akademischen Klinik Parma. Sie identifizierten alle diejenigen Patienten während des Zeitraumes von einem Jahr, die wegen akuter allergischer Reaktionen (akuter allergischer Urtikaria, akutem Angioödem und Urtikaria-Angioödem sowie wegen Anaphylaxie) aufgenommen worden waren. Die mit dieser Studie untersuchte Population umfasste insgesamt 588 erwachsene Patienten, davon mehr Frauen als Männer (328 vs. 260) mit einem mittleren Alter von $43 \pm 18$ Jahre.

Wie sich nun zeigte, waren Patienten mit einem Geburtsdatum im Frühling (März, April oder Mai) erkennbar überrepräsentiert mit 26,2 \% aller Fälle von akuten allergischen Problemen - bei einer Bevölkerung in dieser Region, in der die entsprechende Kohorte von „Frühlingsgeburten" mit einem Anteil von lediglich $23,1 \%$ vertreten ist. Die niedrigste Frequenz fand sich übrigens für Patienten, die im Herbst zur Welt gekommen waren.

Damit hatten die im Frühjahr geborenen Patienten ein um das 1,19- $(=19 \%)$ beziehungsweise 1,12 -Fache $(=12 \%)$ höhere Risiko für eine Aufnahme in der
Notfallambulanz im Vergleich zu den im Herbst Geborenen beziehungsweise gegenüber den anderen zwei Jahreszeiten. Bei besonders schweren Reaktionen wie einem ausgeprägten urtikariellen Angioödem oder einer Anaphylaxie hatten „Frühjahrspatienten“ sogar ein um das 1,86- (= um $86 \%$ ) beziehungsweise

\section{Einfluss der Jahreszeit bei der Geburt} der "Isle of Wight"-Geburtskohorte $(n=367)$. 2016 Mar 12
1,52-Fache (= um $53 \%$ ) erhöhtes Risiko im Vergleich zu „Herbstpatienten“ beziehungsweise Patienten, die in den anderen Jahreszeiten geboren wurden.

Cervellin G et al. Spring season birth is associated with higher emergency department admission for acute allergic reactions. Eur J Intern Med 2016;28:97-101

\section{Kommentar}

Der Augenschein, dass im Frühjahr geborene Personen häufiger und schwerer mit Allergien reagieren, trügt also nicht. Ätiologisch scheint vermutlich der frühe Kontakt mit inhalativen Allergenen (vor allem Pollen) eine Rolle zu spielen

Dr. Ulrich Mutschler

Wie der Geburtszeitpunkt das Allergierisiko beeinflusst, wird offenbar auch von epigenetischen Markern an der DNA geregelt. In einer kürzlich erschienenen Studie von Wissenschaftlern der Universität Southampton in der Zeitschrift Allergy wurden Personen von der Isle of Wight (idyllisch gelegen an der Südküste von England) untersucht. Hierbei handelte es sich um eine Untergruppe von 18-jährigen Teilnehmern aus

Die Arbeitsgruppe um Gabrielle Lockett konnte nachweisen, dass je nach Jahreszeit des Geburtstages bestimmte epigenetische Marker, vor allem bestimmte DNA-Methylierungsmuster, vorlagen. Diese DNA-Methylierungen haben potenziell langfristige Auswirkungen auf die Genexpression und Krankheitsentwicklung. Noch im frühen Erwachsenenalter konnten diese persistierenden Marker gefunden werden.

Definierte Marker hängen mit bestimmten Allergien zusammen, etwa hatten im Herbst geborene Menschen ein höheres Ekzemrisiko als Frühlingskinder, was sich auch bei einer Gruppe holländischer Kindern bestätigen ließ. Die Saison-assoziierten DNA-Methylierungen konnten übrigens bei Neugeborenen noch nicht nachgewiesen werden, was stark darauf hindeutet, dass sie erst postnatal entstehen.

Dr. Ulrich Mutschler

Lockett GA et al. Association of season of birth with DNA methylation and allergic disease. Allergy 